\title{
AN UNUSUAL CONFORMATIONAL CHANGE IN THE FOLDED TRIMETHYLENE/LEONARD LINKER PYRAZOLO $[3,4-d]$ PYRIMIDINE ANALOGUE OF THE THEOPHYLLINE COMPOUND DUE TO STRUCTURAL CHANGES
}

\author{
K. Avasthi ${ }^{1}$, Ruchir Kant ${ }^{1}$, S. Aswal ${ }^{1}$, A.K. Tewari ${ }^{1}$, U. Yadav ${ }^{1}$, \\ U.D. Misra ${ }^{2}$, P.R. Maulik ${ }^{1}$ \\ ${ }^{1}$ CSIR - Central Drug Research Institute (CDRI), Sector-10, Jankipuram Extension, Sitapur Road, Lucknow \\ 226031, India \\ E-mail: kavasthi@rediffmail.com \\ ${ }^{2}$ Department of Physics, University of Lucknow, Lucknow, 226007, (U.P.)
}

Received March, 7, 2014

The title compound $\mathrm{C}_{29} \mathrm{H}_{28} \mathrm{~N}_{8} \mathrm{O}_{4}, 1,1^{\prime}$-(propane-1,3-diyl)bis(5-benzyl-7-methyl-1 $\mathrm{H}$-pyrazolo[3,4d]pyrimidine-4,6(5H,7H)-dione) is characterized by single crystal X-ray diffraction. It crystallizes in the centrosymmetric space group $P \overline{1}$, with two molecules in the unit cell. There is one formula unit in the asymmetric unit with a folded conformation due to arene interaction and an unusually large angle of $124^{\circ}$ in the propylene linker. The crystal structure is stabilized due to the presence of $\pi-\pi$ and $\mathrm{C}-\mathrm{H}$...O interactions.

DOI: $10.15372 / \mathrm{JSC} 20150730$

K e y w o r d s: propylene linker, arene interaction, single crystal X-ray diffraction studies.

The crystal structure of 1,3-bis(theophyllin-8-yl)propane (1, Fig. 1), reported in 1971, is generally considered to be the first propylene linker compound which shows an unusual intramolecular folding in addition to the extensive H-bonding [1]. Compound $\mathbf{1}$, which crystallizes as a hydrate, shows six intermolecular hydrogen-bonding contacts per molecule, two of which involve the NH group, two involve the water molecule, and the remaining two are involved in the $\mathrm{C}-\mathrm{H} \ldots \mathrm{O}$ bonding. In addition, there is disorder in the linker, and the angle at the central carbon atom is unusually large being 121.2(8) ${ }^{\circ}$. Caffeine (7-methyl theophylline) having the same ring system, is the most widely consumed mood-altering substance and acts as a CNS stimulant. Interestingly, it is well documented that caffeine type molecules show intermolecular stacking and both modes: (i) a five-membered ring over a five-membered ring and a six-membered ring over a six-membered ring and (ii) a five-membered ring over a six-membered ring and a six-membered ring over a five-membered ring [2]. Compound $\mathbf{1}$ shows the first pattern. On the other hand we reported the structure of 1,3-bis(8-chlorotheophyllin-7yl)propane 2, having the same bicyclic system as that of compound $\mathbf{1}$ (Fig. 1) showing a fully extended (open) conformation without any intramolecular stacking. The structure of $\mathbf{2}$ has no disorder and the angle at the central carbon atom in the propylene linker is $112.3(2)^{\circ}$, which is normal. The main differences between two compounds ( $\mathbf{1}$ and $\mathbf{2}$, Fig. 1) are: (i) the position of the propylene linker; (ii) the presence of ionizable $\mathrm{H}$ in $\mathbf{1}$ and its absence in 2; and (iii) the presence of $\mathrm{Cl}$ in $\mathbf{2}$ and its absence in 1 (Fig. 1).

Experimental. The conformation of title compound $\mathbf{8 b}, \mathrm{C}_{29} \mathrm{H}_{28} \mathrm{~N}_{8} \mathrm{O}_{4}$, (systematic name: 1,1'-(propane-1,3-diyl)bis(5-benzyl-7-methyl-1 $H$-pyrazolo[3,4- $d]$ pyrimidine-4,6(5H,7H)-dione) was determined

(C) Avasthi K., Kant Ruchir, Aswal S., Tewari A.K., Yadav U., Misra U.D., Maulik P.R., 2015 


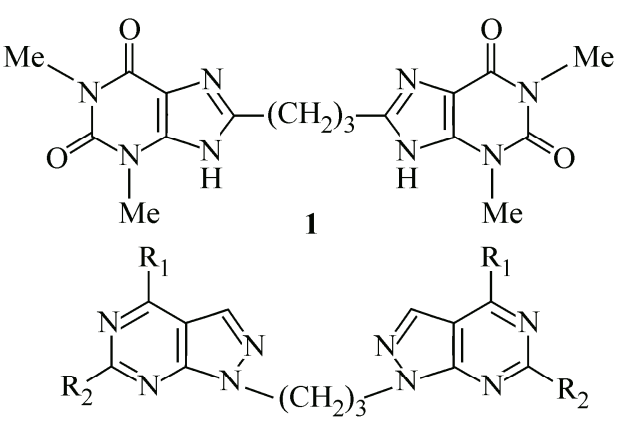

3a: $\mathrm{R}_{1}=\mathrm{R}_{2}=\mathrm{SMe}$;

3b: $\mathrm{R}_{1}=\mathrm{R}_{2}=\mathrm{SEt}$;

3c: $\mathrm{R}_{1}=\mathrm{R}_{2}=\mathrm{S}-$ iso-Pr;

3d: $\mathrm{R}_{1}=\mathrm{OEt}, \mathrm{R}_{2}=\mathrm{SMe}$;

3e: $\mathrm{R}_{1}=\mathrm{O}-$ iso-Pr, $\mathrm{R}_{2}=\mathrm{SMe}$;

3f: $\mathrm{R}_{1}=\mathrm{OMe}, \mathrm{R}_{2}=\mathrm{SO}_{2} \mathrm{Me}$;

3g: $\mathrm{R}_{1}=\mathrm{OEt}, \mathrm{R}_{2}=\mathrm{SO}_{2} \mathrm{Me}$;

3h: $\mathrm{R}_{1}=\mathrm{O}-$ iso-Pr, $\mathrm{R}_{2}=\mathrm{SO}_{2} \mathrm{Me}$;

3i: $\mathrm{R}_{1}=\mathrm{O}-$ iso- $\mathrm{Pr}, \mathrm{R}_{2}=\mathrm{SO}_{2} \mathrm{Et}$;

3j: $\mathrm{R}_{1}=\mathrm{R}_{2}=\mathrm{OMe}$

3k: $\mathrm{R}_{1}=\mathrm{Cl}, \mathrm{R}_{2}=\mathrm{SMe}$;

3l: $\mathrm{R}_{1}=\mathrm{CN}, \mathrm{R}_{2}=\mathrm{SMe}$<smiles>Cn1c(=O)c2c(nc(Cl)n2C)n(C)c1=O</smiles><smiles>[R]n1c(S(C)(=O)=O)nc2c(cnn2C)c1=O</smiles>

4a: $\mathrm{R}=\mathrm{H} ; \mathbf{4 b}: \mathrm{R}=\mathrm{Me}$

4c: $\mathrm{R}=\mathrm{Et} ; 4 \mathbf{d d}: \mathrm{R}=\mathrm{CH}_{2} \mathrm{Ph}$<smiles>Nc1ncnc2c1ncn2CCCCn1cnc2c(N)ncnc21</smiles>

5

Fig. 1. Xanthine- and pyrazolo[3,4- $d]$ pyrimidine-based propylene linker compounds and the synthesis of new propylene linker compounds

by single crystal X-ray diffraction studies. Compound $\mathbf{8 b}$ was synthesized according to the literature method [3]. Thus, on oxidation $\mathbf{4 d}$ gave sulfone $\mathbf{6 b}$ which was refluxed with aqueous alkali to give $\mathbf{7 b}$. Compound $\mathbf{7 b}$ was treated with methyl iodide to give desired product $\mathbf{8 b}$. Diffraction quality crystals were obtained by slow evaporation of the ethyl acetate solution at room temperature.

$\mathbf{X}$-ray crystal structure determination of $\left(\mathbf{C}_{29} \mathbf{H}_{28} \mathbf{N}_{8} \mathbf{O}_{4}\right)$. The unit cell determination $\left(1.79^{\circ}<\theta<\right.$ $<24.99^{\circ}$ ) and the intensity data collection were performed on a Bruker P4 diffractometer at 293(2) K for compound $\mathbf{8 b}$. The structure solution was performed by direct methods and refined by full-matrix least-squares methods on $F^{2}$. Programs: XSCANS [4], SHELXTL-NT [5]. CCDC (deposit No 954043) contains the supplementary crystallographic data. Crystallographic details of the data collection and the structure refinement: $\mathrm{C}_{29} \mathrm{H}_{28} \mathrm{~N}_{8} \mathrm{O}_{4}, M=552.59$, triclinic, space group $P \overline{1}, \lambda=0.71073 \AA$, $a=9.107(1), b=12.968(2), c=13.426(2) \AA, \alpha=64.38(1), \beta=71.74(1), \gamma=70.01(1)^{\circ}, V=1317.7(3) \AA^{3}$, $Z=2, d_{\mathrm{c}}=1.393 \mathrm{~g} / \mathrm{cm}^{3}, \mu=0.10 \mathrm{~mm}^{-1}, F(000)=580$, crystal size $0.30 \times 0.28 \times 0.15 \mathrm{~mm}, \theta$ range 1.79 $24.99^{\circ}$, index ranges $-10 \leq h \leq 1,-14 \leq k \leq 13,-15 \leq l \leq 15,5471$ reflections collected, 4532 indepen$\operatorname{dent}\left(R_{\text {int }}=0.0178\right), 97.8 \%$ completeness, 0.9856 and 0.9715 max and min transmission, 373 parameters, GOOF $=1.015$, final $R_{1}=0.0592, w R_{2}=0.1348(I>2 \sigma(I)), R_{1}=0.1128, w R_{2}=0.1607$ (all data), $\Delta \rho_{\max } / \Delta \rho_{\min }=0.416 /-0.408 \mathrm{e} / \AA^{3}$.

Hydrogen bonding distances and angles are listed in Table 1. Further details of the crystal structure investigation can be obtained free of charge from www.ccdc.cam.uk/conts/retrieving.html [or from the Cambridge Crystallographic Data Center, 12 Union Road, Cambridge, CB2 1EZ, U. K; Fax: (internat.) +44-1223/336-033; E-mail: deposit@ccdc.cam.ac.uk.]

Results and discussion. In 1995, we reported the synthesis of the first propylene linker compound (3a, Fig. 1) based on the pyrazolo[3,4$d$ ]pyrimidine (PP) core [6], which is isomeric with the purine ring system found in DNA/RNA and xanthines, as a new flexible model for studying

T a b l e 1

Geometrical parameters for hydrogen bonds ( $\AA$, deg.)

\begin{tabular}{c|c|c|c|c}
\hline $\mathrm{D}-\mathrm{H} \cdots \mathrm{A}$ & $\mathrm{D}-\mathrm{H}$ & $\mathrm{H} \cdots \mathrm{A}$ & $\mathrm{D} \cdots \mathrm{A}$ & $\mathrm{D}-\mathrm{H} \cdots \mathrm{A}$ \\
\hline $\mathrm{C} 10-\mathrm{H} 10 \mathrm{~B} \cdots \mathrm{O} 1^{\mathrm{i}}$ & 0.97 & 2.71 & 3.41 & 129 \\
$\mathrm{C} 36-\mathrm{H} 36 \cdots \mathrm{O} 2^{\mathrm{ii}}$ & 0.93 & 2.55 & 3.25 & 132 \\
$\mathrm{C} 24-\mathrm{H} 24 \cdots \mathrm{O} 4^{\mathrm{iii}}$ & 0.93 & 2.53 & 3.22 & 131
\end{tabular}

Symmetry codes: ${ }^{\mathrm{i}}-1+x, y, z ;{ }^{\text {ii }} x, 1+y, z$; ${ }^{\text {iii }} 1+x$, $-1+y, z$. 
aromatic $\pi-\pi$ interactions (APPI). Intramolecular folding indicated by the ${ }^{1} \mathrm{H}$ NMR analysis in solution was confirmed by its solid state X-ray crystallographic analysis [7]. The subsequent work was extended to more PP core-based propylene linker compounds related to 3a (Fig. 1) [8 ]. Intramolecular folding in one of these compounds due to $\pi-\pi$ interactions (4b, Fig. 1) was also confirmed by its solid state X-ray crystallography [9]. The subsequent work on more than a dozen PP core-based propylene linker compounds ( $\mathbf{3 b}-\mathbf{3 j}, \mathbf{4} \mathbf{c}$ and $\mathbf{4 d}$, Fig. 1), established the robustness of the unusual $\mathrm{U}$ motif present in two original compounds [ 10 ]. On the other hand, X-ray crystallographic analyses of the last two compounds having chloro (3k, Fig. 1) or cyano (3l, Fig. 1) groups do not show similar intramolecular stacking [ 10 ]. In all these symmetrical compounds $(\mathbf{3 a}-\mathbf{3 j}, \mathbf{4 b}-\mathbf{4 d}$, Fig. 1) the linker position is between $N^{1}$ atoms of the $\mathbf{P P}$ core, which corresponds to $N^{9}$ position in the purine (in DNA/RNA) or xanthine system in theophylline. More importantly, none of these PP core-based compounds ( 3 and 4, Fig. 1) show a disorder in the propylene linker and the angle at the central carbon atom is in the narrow range of $113.5-115.3^{\circ}$. Finally, the crystal structure of 1,3-bis(adenine-9yl)propane (5, Fig. 1) having the same bicyclic system as $\mathbf{1}$ and $\mathbf{2}$ (Fig. 1), whose structure was long back proposed to be folded in solution [11 ], shows a folded conformation though the angle at the central carbon atom in the propylene linker is somewhat large being $116^{\circ}$ [12].

Considering the increasing interest in arene interactions over the last two decades [13,14], coupled with all above facts, especially that both $\mathbf{3}(\mathbf{3 a}-\mathbf{3 j}$, Fig. 1), derived $\mathbf{4}$ (4b-4d, Fig. 1), and related 5 (5, Fig. 1), with the comparable linker position, show intramolecular stacking due to the $\pi-\pi$ interaction, it became of interest to know the folding behavior of $\mathbf{8}$ (Fig. 1), a theophylline analogue of 1. If found folded, what will be its conformation and angle at the central carbon atom in new propylene linker compound $\mathbf{8}$ (Fig. 1) in comparison to structurally related compounds (1 and 2, Fig. 1)? Desired compound $\mathbf{8 a}$ (Fig. 1) was prepared from $\mathbf{4 b}$, however, all efforts to get a crystal suitable for X-ray crystallography were not successful, therefore it will not be described here. Next, we prepared benzyl analogue 8b (Fig. 1) from known 4d [15 ] via simple chemical manipulations. Compound $\mathbf{8 b}$ gave good diffraction quality crystals; the conformation of this compound, as determined by X-ray crystallography, is shown in Fig. 2 (the asymmetric unit contains one formula unit with a folded conformation). To our delight, the intramolecular stacking is present; however, the conformation is different as compared to previous compounds, $(\mathbf{3 a}-\mathbf{3} \mathbf{j}$ and $\mathbf{4 b}-\mathbf{4 d}$, Fig. 1). The conformation of $\mathbf{8 b}$ is such that the distance between two centroids of five-membered pyrazolo cores is minimum ( $3.38 \AA$ ) and the distance between two centroids of six-membered pyrimidine cores is maximum (4.79 $\AA$ ) (Fig. 2).

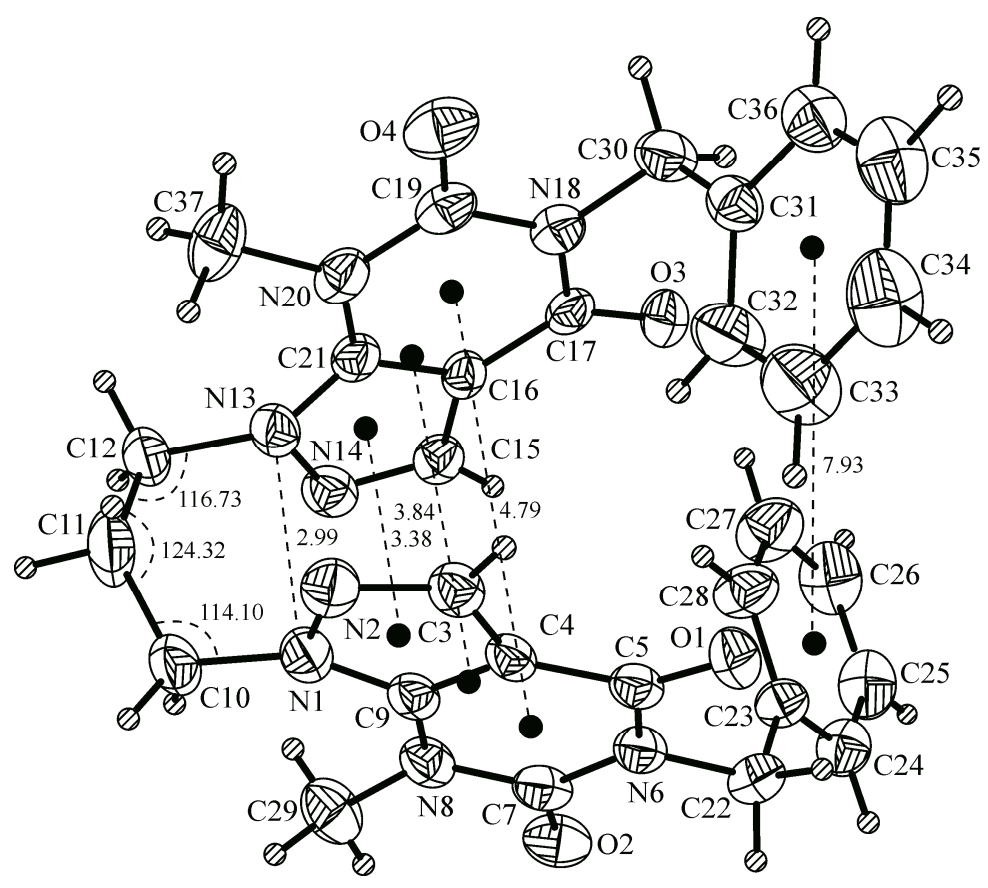

Fig. 2. A displacement ellipsoid plot (30\% probability), showing the molecular structure of $\mathbf{8 b}$ and atom labelling 
This folded conformation differs from the previous PP core-based compounds in two aspects. First, the anti conformation though present in all folded compounds (except $\mathbf{2} \mathbf{h}$ which is in the syn conformation) of $\mathbf{8 b}$ is very different. Second, the distance between two $\mathrm{N}$ atoms bearing the linker is much less $(2.99 \AA)$ than the same distance $(3.33 \AA$ ) between two $\mathrm{N}$ atoms in $\mathbf{4 d}$, structurally relevant to $\mathbf{8 b}$. This clearly indicates that large benzyl groups cannot be a reason for the new conformation of $\mathbf{8 b}$. Actually, this distance is comparable to the corresponding distance (3.09 $\AA$ ) in $\mathbf{3 h}$, the odd member in the syn conformation of series $\mathbf{3}$.

In fact, this decreased distance can be favourably compared with $2.93 \AA$ seen in ethylene linker compounds which show the intramolecular folding due to arene interaction [16]. Finally, the angle at the central carbon atom in the propylene linker is unusually large being $124^{\circ}$; in fact, it is even larger than $121.2(8)^{\circ}$, reported for the first propylene linker folded compound (1). Interestingly, this conformation is close to that of compound 5. This study further confirms our earlier contention that the PP core is a versatile system for studying/understanding the intramolecular $\pi-\pi$ interaction since it can tolerate wide structural changes as demonstrated by three types of compounds $(\mathbf{3 a}-\mathbf{3 j}, \mathbf{4} \mathbf{b}-\mathbf{4 d}$, and $\mathbf{8 b}$, Fig. 1). The hydrogen-bonding geometry ( $\AA$, deg.) for compound $\mathbf{8 b}$ is shown in Table 1. Distances and angles are within a range of the recent report [ 17 ].

In conclusion, a new structural type (8) related to two existing types (3 and 4 ) based on the same PP core, which is isomeric with the biologically important purine system, has been added for studying the arene interaction at both molecular and supramolecular levels. Above all, the new type (8) as well as two existing types ( 3 and $\mathbf{4}$ ) also shows the intramolecular arene interaction, however, the conformation is quite different and the angle in the propylene linker is also unusually large $\left(124^{\circ}\right)$. K. Avasthi is grateful to DST, New Delhi, India for financial support (grant no. SR/S1/OC-14/2010). P.R. Maulik thanks CSIR, New Delhi, for the Grant-in-aid of Emeritus Scientist ship Scheme [No.: 21(0766)/09/EMR-II]. CDRI communication no. 8642.

\section{REFERENCES}

1. Rosen L.S., Hybl A. // Acta Crystallogr. - 1971. - B27. - P. 952 - 960.

2. Falk M., Chew W., Walter J.A., Kwiatkowski W., Barclay K.D., Klassen G.A. // Can. J. Chem. - 1998. - 76, N 1. - P. $48-56$.

3. Avasthi K., Chandra T., Rawat D.S., Bhakuni D.S. // Indian J. Chem. - 1998. - 37B. - P. $1228-1233$.

4. Siemens XSCANS, Siemens Analytical X-ray Instruments Inc., Madison, Wisconsin, USA, 1994.

5. Bruker SHELXTL, Bruker AXS Inc., Madison, Wisconsin, USA, 1997.

6. Avasthi K., Chandra T., Bhakuni D.S. // Indian J. Chem. - 1995. - 34B. - P. 944 - 949.

7. Biswas G., Chandra T., Avasthi K., Maulik P.R. // Acta Crystallogr. - 1995. - 51C. - P. 2453/2454.

8. Avasthi K., Rawat D.S., Chandra T., Bhakuni D.S. // Indian J. Chem. - 1998. - 37B. - P. 754 - 759.

9. Maulik P.R., Avasthi K., Biswas G., Biswas S., Rawat D.S., Sarkhel S., Chandra T., Bhakuni D.S. // Acta Crystallogr. - 1998. - 54C. - P. $275-277$.

10. Avasthi K., Farooq S.M., Raghunandan R., Maulik P.R. // J. Mol. Struct. - 527, Nos. 1-3. - P. 27 - 36.

11. Browne D.T., Eisinger J., Leonard N.J. // J. Am. Chem. Soc. - 1968. - 90, N 26. - P. $7302-7323$.

12. Garcia-Raso A., Fiol J.J., Badenas F., Solans X., Font-Bardia M. // Polyhedron. - 1999. - 18, N 6. - P. 765 772 .

13. Watt M., Hardebeck L.K.E., Kirkpatrick C.C., Lewis M. // J. Am. Chem. Soc. - 2011. - 133, N 11. - P. 3854 3862.

14. Wheeler S.E. // J. Am. Chem. Soc. - 2011. - 133, N 26. - P. 10262 - 10274.

15. Avasthi K., Tewari A., Rawat D.S., Sharon A., Maulik P.R. // Acta Crystallogr. - 2002. - 58C. - P. o494 o495.

16. Avasthi K., Kumar A., Aswal S., Kant R., Raghunandan R., Maulik P.R., Khanna R.S., Ravikumar K. // CrystEngComm. - 2012. - 14, N 2. - P. $383-388$.

17. Wood P.A., Allen F.H., Pidcock E. // CrystEngComm. - 2009. - 11, N 8. - P. 1563 - 1571. 